Brazilian Journal
of Chemical
Engineering

\title{
3D-CFD SIMULATION AND NEURAL NETWORK MODEL FOR THE $j$ AND $f$ FACTORS OF THE WAVY FIN-AND-FLAT TUBE HEAT EXCHANGERS
}

\author{
M. Khoshvaght Aliabadi, M. Gholam Samani, F. Hormozi* and A. Haghighi Asl \\ School of Chemical, Petroleum and Gas Engineering, Semnan University, \\ Phone: + 98 9123930495, Fax: + 98 2313354136, Semnan, I. R. Iran. \\ E-mail: fhormozi@semnan.ac.ir
}

(Submitted: August 3, 2010 ; Revised: February 4, 2011 ; Accepted: March 18, 2011)

\begin{abstract}
A three dimensional (3D) computational fluid dynamics (CFD) simulation and a neural network model are presented to estimate the behaviors of the Colburn factor $(j)$ and the Fanning friction factor $(f)$ for wavy fin-and-flat tube (WFFT) heat exchangers. Effects of the five geometrical factors of fin pitch, fin height, fin length, fin thickness, and wavy amplitude are investigated over a wide range of Reynolds number $(600 \leq \mathrm{Re} \leq 7000)$. The CFD simulation results express that the geometrical parameters of wavy fins have significant effects on the $j$ and $f$ factors as a function of Reynolds number. The computational results have an adequate accuracy when compared to experimental data. The accuracy of the calculations of the $j$ and $f$ factors are evaluated by the values of the absolute average relative deviation (AARD), being respectively $3.8 \%$ and $8.2 \%$ for the CFD simulation and $1.3 \%$ and $1 \%$ for the neural network model. Finally, new correlations are proposed to estimate the values of the $j$ and $f$ factors with $3.22 \%$ and $3.68 \%$ AARD respectively.

Keywords: Wavy fin-and-flat tube; $j$ factor; $f$ factor; CFD simulation; Neural network.
\end{abstract}

\section{INTRODUCTION}

Compact heat exchangers are widely employed in industry, especially as gas-to-gas or liquid-to-gas heat exchangers in gas heating or cooling processes involving condensers and evaporators such as in airconditioning, refrigeration industry, automotive radiators, intercoolers of compressors, oil coolers and electronic applications. Some compact heat exchangers are categorized as plate fin-and-tube, wavy fin-and-round tube, and wavy fin-and-flat tube (WFFT) heat exchangers.

WFFT type heat exchangers have many applications in the field of thermal and chemical engineering, having the potential for an enhancement in thermal-hydraulic performance. The main thermal resistance of these heat exchangers is found on the gas side; thus, improving the configuration or geometrical parameters can elevate the performance of the exchanger by increasing heat transfer. The surface corrugations of these exchangers can have either triangular, sinusoidal or trapezoidal profiles.

A comparison among plate, wavy and louver fin surfaces has been experimentally carried out on the air-side heat transfer and pressure drop characteristics (Yan and Sheen, 2000), where it was shown that the louver type had greater values of the $j$ and $f$ factors than the plate fin at the same Reynolds numbers. Moreover, the wavy fin heat exchanger displayed the highest $j / f$ ratio for the $R e \leq 1500$ regime. Zhu and $\mathrm{Li}$ (2008) analyzed numerically the four typical types of rectangular plain, strip offset, perforated, and wavy type plate-fin heat exchangers in a laminar flow. Also, three dimensional CFD

*To whom correspondence should be addressed 
simulations were carried out for the plate fin-andtube heat exchanger to examine the heat transfer and the pressure drop behaviors under changes in fin geometry (Erek et al., 2005; Şahin et al., 2007).

Xie et al. (2009) studied the effect of Reynolds number, number of tube rows, tube diameter, tube pitches, and fin pitch in a multi-stage compressor by computational methods. Vortex generators behind the tubes were investigated, both experimentally and numerically, in plate-fin and tube heat exchangers in order to find the effects of different span angles for different ranges of the Reynolds number (Leu et al., 2004). A study of the Colburn factor and the friction factor based on the fin collar outside diameter in a herringbone wavy fin configuration at various fin thicknesses and Reynolds numbers has been conducted by an experimental approach (Wongwises and Chokeman, 2005). Tian et al. (2009) applied the (RNG) $\mathrm{k}-\varepsilon$ model to design wavy fin-and-tube heat exchangers with punched delta winglets which have three-row round tubes in staggered or inline arrangements using a three dimensional simulation. Wang et al. (2002) proposed an appropriate empirical correlation with the use of regression analysis for the air side performance of herringbone waves in various patterns.

Experimental results have shown that the heat transfer coefficient, the pressure drop, the $j$ factor, and the $f$ factor have an increasing trend from plate fin-and-tube to wavy fin-and-tube heat exchangers and reach their highest magnitude in compounded fin exchangers (Wena and Ho, 2009). Huzayyin et al. (2007) experimentally studied the change of operating conditions in wavy fin-and-tube direct expansion air coils under cooling and dehumidifying conditions in order to find their effects on the airside performance of the coils such as their heat transfer coefficient, pressure drop, etc.. Investigations on the fin spacing and tube rows have explained the fact that increasing the Reynolds number leads to a decreased importance of the effects of geometrical parameters and the inlet conditions (Pirompugd et al., 2006).

The numerical simulation results implied that with the increase of the wave angles, decrease of the fin pitch, and decrease of the tube row number, the heat transfer of the finned tube bank enhances, but with some penalty in pressure drop (Tao et al., 2007). Two- and three-dimensional numerical simulations have been performed on rectangular wavy-plate-fin cores to determine the velocity and temperature distributions, the $j$ factor and the isothermal $f$ factor in the range of low Reynolds number (10-1000), wall-corrugation severity $(0.125-0.5)$, and fin spacing (0.1-3) (Zhang et al., 2004; Manglik et al., 2005). A control volume finite-difference method was also presented to estimate numerically the compactness and the heat transfer enhancement effectiveness $(j / f)$ for different Reynolds (10-1000) and Prandtl $(5,35$, and 150) numbers (Metwally and Manglik, 2004). Dong Junqi et al. investigated experimentally the effects of geometrical parameters on the heat transfer coefficient and the pressure drop in the wavy fin-and-flat tube (Dong et al., 2007b), offset strip fin (Dong et al., 2007c), and multi-louvered fin heat exchangers (Dong et al., 2007a).

The above works present effective factors for heat transfer and pressure drop of the plate fin, wavy finand-round tube and WFFT heat exchangers. Several experimental and numerical studies exist for the plate fin and wavy fin-and-round tube exchangers, whereas there are few computational methods applied to the WFFT models. However, the effect of geometrical parameters has not been previously analyzed numerically except for fin spacing, wave length and wavy amplitude in laminar flow $(\mathrm{Re} \leq 1000)$ with a two-dimensional approach in WFFT heat exchangers.

The major contribution of this work involves the investigation of a three-dimensional numerical simulation of triangular sinusoidal WFFT heat exchangers in order to illustrate the effects of geometrical parameters such as fin pitch $\left(\mathrm{F}_{\mathrm{p}}\right)$, fin height $\left(F_{h}\right)$, fin length $\left(L_{d}\right)$, fin thickness $(\delta)$ and wavy amplitude (2A) over a wide range of Reynolds number $(600 \leq \mathrm{Re} \leq 7000)$ with laminar and turbulent fluid flow regimes. In addition, a neural network is used to estimate the $j$ and $f$ factor values in the mentioned heat exchanger. A neural network model and a comparison of the model with experimental and CFD simulation results had not previously been applied to predict heat transfer and flow friction of wavy fin-and-flat tube heat exchangers in the open literature. Two correlations are presented to predict the $j$ and $f$ factor values for this type of heat exchangers. A typical wavy fin that is analyzed in this study is shown in Fig. 1.

\section{DEFINITIONS AND MODELING}

\section{Model Description}

The model studied consists of a segment of a triangular sinusoidal wavy fin with a defined fin thickness and with air in contact with both of the wavy fin sides. Only one section of the fin and fluid 
are modeled between two symmetry boundary conditions since the given model of the fin is repeated regularly.

The geometrical configuration and terminology of the WFFT heat exchangers is depicted in Fig. 2 where fin pitch $F_{P}$, fin height $F_{h}$, fin length $L_{d}$, wave amplitude 2A, and fin thickness $\delta$ are used to describe the exchanger configuration. Fifteen types of fin are analyzed and the specifications of the fins are detailed in Table 1, where rows 1 to 11 are from the literature (Dong et al., 2007b) and rows 12 to 15 are presented in this work.

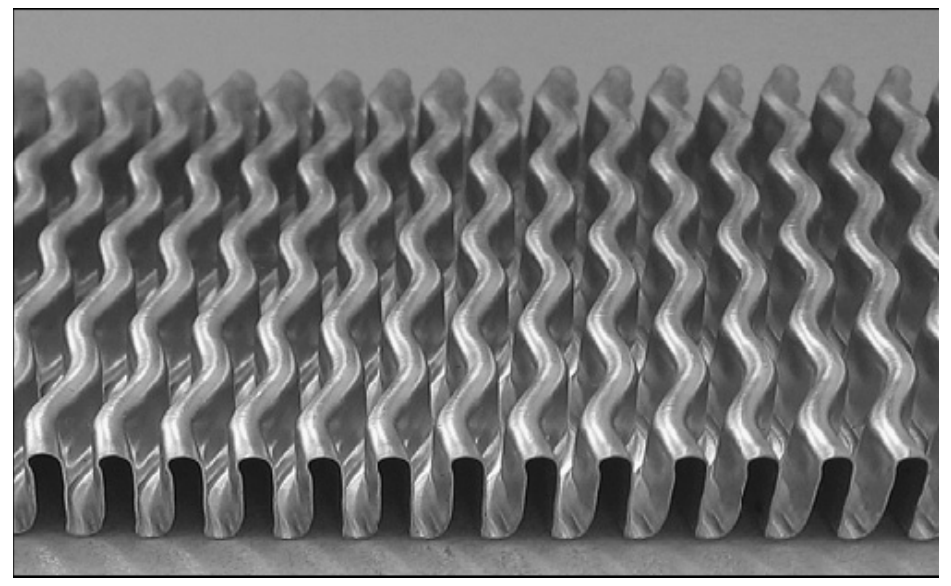

Figure 1: View of an analyzed sinusoidal wavy fin (Dong et al., 2007b).
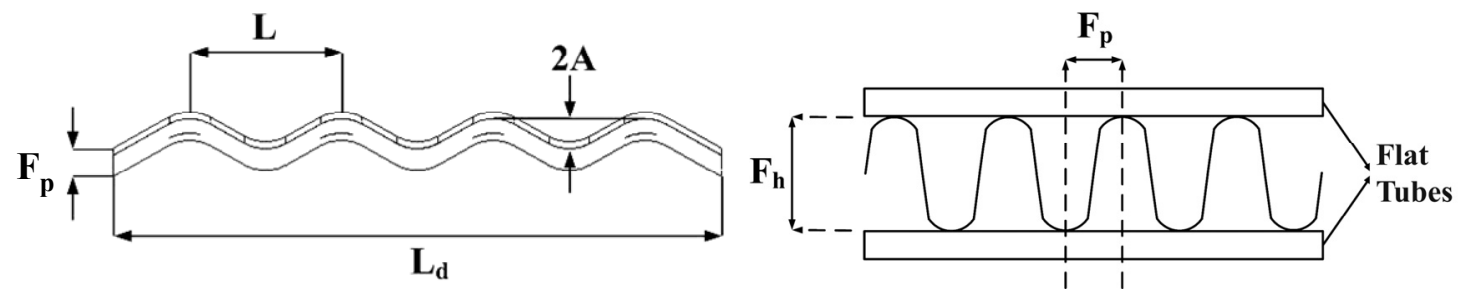

Figure 2: Schematic view of wavy fin dimensions.

Table 1: Parameters of the studied fin models [mm].

\begin{tabular}{|c|c|c|c|c|c|c|}
\hline Model No. & $\begin{array}{c}\text { Fin pitch } \\
\left(\mathrm{F}_{\mathrm{p}}\right)\end{array}$ & $\begin{array}{c}\text { Fin height } \\
\left(F_{h}\right)\end{array}$ & $\begin{array}{c}\text { Fin length } \\
\left(L_{d}\right)\end{array}$ & $\begin{array}{c}\text { Fin thickness } \\
(\delta)\end{array}$ & $\begin{array}{c}\text { Wave amplitude } \\
(2 \mathrm{~A})\end{array}$ & $\begin{array}{c}\text { Wave length } \\
\text { (L) }\end{array}$ \\
\hline 1 & 2.0 & 8.0 & 65.0 & 0.2 & 1.5 & 10.8 \\
\hline 2 & 2.25 & 8.0 & 65.0 & 0.2 & 1.5 & 10.8 \\
\hline 3 & 2.5 & 8.0 & 65.0 & 0.2 & 1.5 & 10.8 \\
\hline 4 & 2.0 & 8.0 & 53.0 & 0.2 & 1.5 & 10.8 \\
\hline 5 & 2.25 & 8.0 & 53.0 & 0.2 & 1.5 & 10.8 \\
\hline 6 & 2.5 & 8.0 & 53.0 & 0.2 & 1.5 & 10.8 \\
\hline 7 & 2.0 & 7.0 & 43.0 & 0.2 & 1.5 & 10.8 \\
\hline 8 & 2.25 & 7.0 & 43.0 & 0.2 & 1.5 & 10.8 \\
\hline 9 & 2.5 & 7.0 & 43.0 & 0.2 & 1.5 & 10.8 \\
\hline 10 & 2.0 & 8.0 & 43.0 & 0.2 & 1.5 & 10.8 \\
\hline 11 & 2.0 & 10.0 & 43.0 & 0.2 & 1.5 & 10.8 \\
\hline 12 & 2.0 & 7.0 & 43.0 & 0.3 & 1.5 & 10.8 \\
\hline 13 & 2.0 & 7.0 & 43.0 & 0.1 & 1.5 & 10.8 \\
\hline 14 & 0.2 & 8.0 & 65.0 & 0.2 & 2.0 & 10.8 \\
\hline 15 & 0.2 & 8.0 & 65.0 & 0.2 & 1.0 & 10.8 \\
\hline
\end{tabular}




\section{Boundary Conditions}

The velocity inlet boundary condition is defined at the front surface, since air enters from this cross sectional area. The air velocity values for each model depend on Reynolds number, which is altered from 600 to 7000 . The air is exhausted from the back side of the heat exchanger, so the outflow boundary condition is applied to this surface. Symmetrical boundary conditions have been used for the left and right surface sides of the model due to the symmetry assumption. For the other surfaces, non-slip wall boundary conditions have been applied. The middle surface (fin) is considered to be a coupled wall condition and a uniform temperature is utilized for the top and bottom surfaces. These boundary conditions make the model near to real heat exchanger situations. A schematic view of the three dimensional domain and boundary conditions is presented in Fig. 3. Gravity effects on fluid flow are assumed to be negligible in the wavy channel.

The material of the fin and flat tube is considered to be steel. The physical properties of the steel are assumed to be constant quantities, whereas the air properties are taken to be a function of temperature.

\section{Mesh Generation}

Because the effect of geometrical parameters has been investigated in this simulation and the mesh numbers are varied with changes in the investigated geometrical parameters, it is crucial to prove that the numerical results are independent of the grid size and type. Therefore, sensitivity analyses were carried out on model 1 and model 7 for $\mathrm{Re}=4830$ and $\mathrm{Re}=4950$, respectively. Three different structured mesh numbers were studied in order to investigate the influence of the mesh numbers on the computational results, the mesh numbers being approximately 980000,1100000 , and 1260000 cells for model 1 and 910000, 780000, and 650000 cells for model 7. The results for the three sets of mesh number are presented in Table 2. The errors of the $j$ and $f$ factors are less than $3 \%$. Thus, the accepted mesh number in the computational domain is the minimum number of meshes for the reduction in the computational time. The grid system of the model is shown in Fig. 4. Only the front and top views of the region are presented in this figure for simplicity.

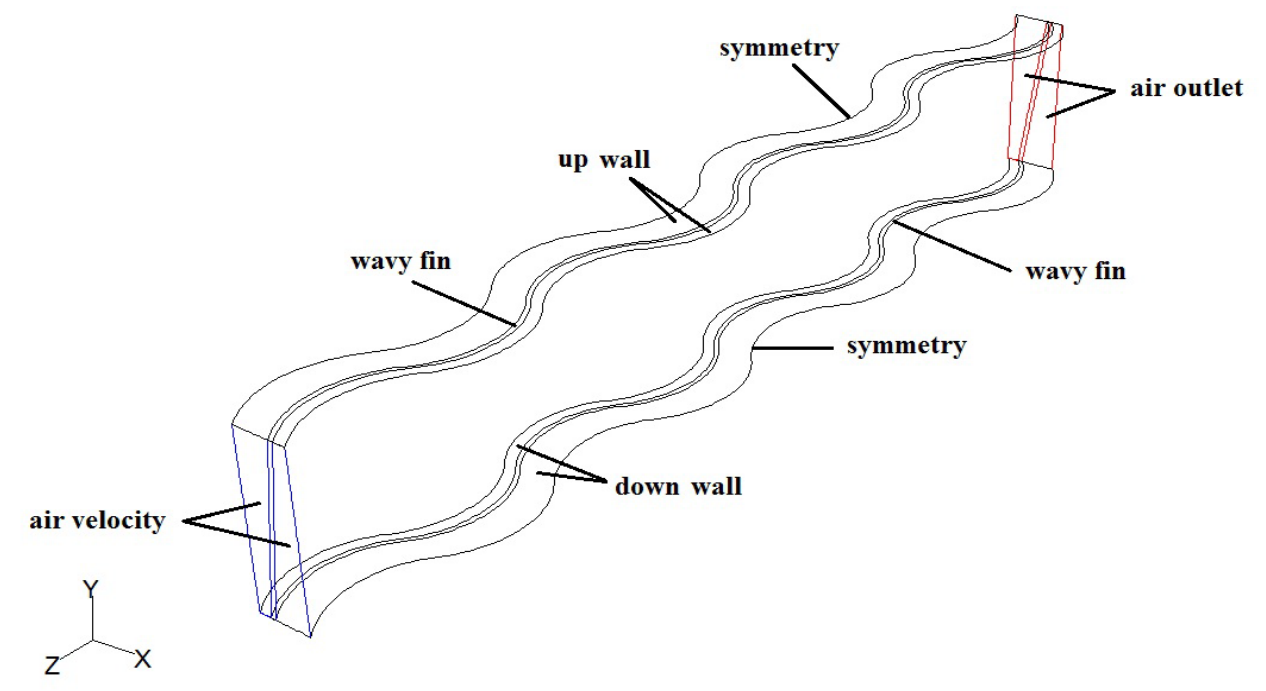

Figure 3: Computational domain and boundary conditions

Table 2: $\boldsymbol{j}$ factor and $\boldsymbol{f}$ factor values with different mesh numbers for models 1 and 7.

\begin{tabular}{|c|c|c|c|}
\hline Model & Number of meshes & $\boldsymbol{j}$ & $\boldsymbol{f}$ \\
\hline \multirow{3}{*}{1} & 980,000 & 0.004948 & 0.037908 \\
& $1,100,000$ & 0.005002 & 0.039351 \\
\hline \multirow{2}{*}{7} & $1,260,000$ & 0.005098 & 0.036889 \\
& 650,000 & 0.005196 & 0.037051 \\
& 780,000 & 0.005202 & 0.038112 \\
\hline
\end{tabular}



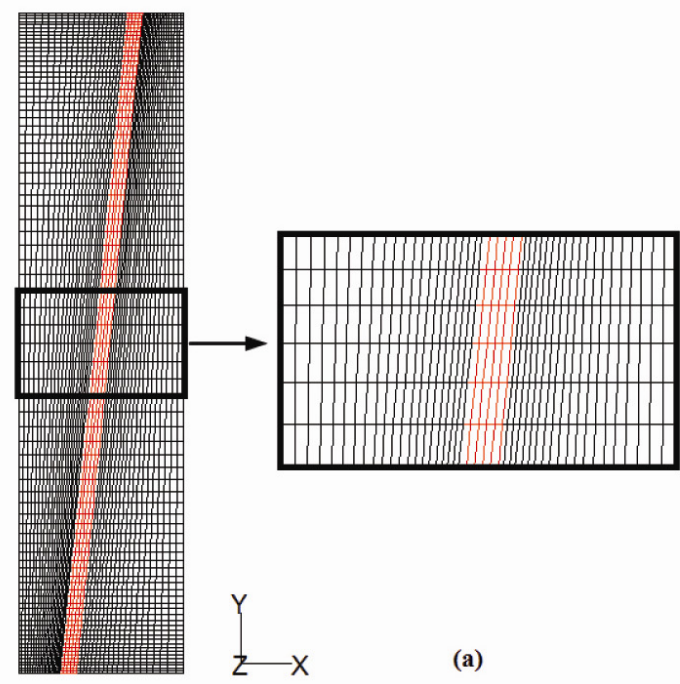

(a)

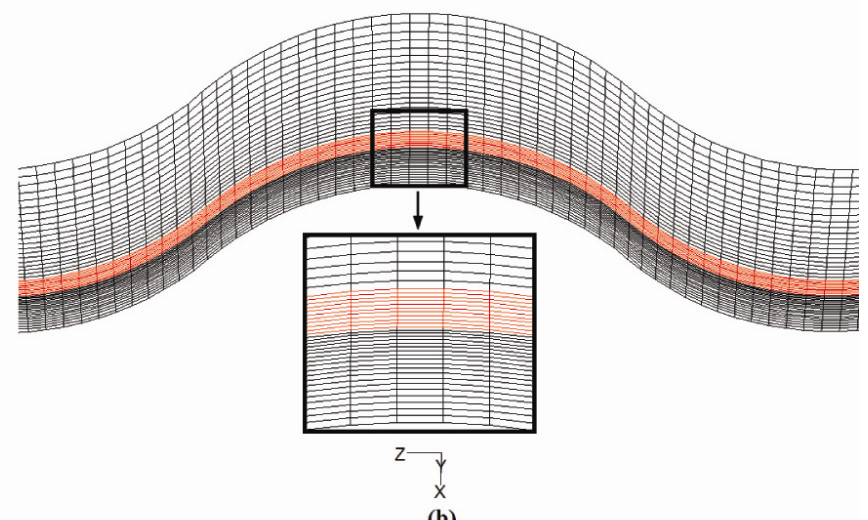

Figure 4: The parts of the grid system: (a) front view (b) top view

\section{MATHEMATICAL FORMULATION AND NUMERICAL METHODS}

\section{Governing Equations}

The air flow in the computational domain is supposed to be at steady state and incompressible at the mean temperature. The stream regime is assumed to be laminar before the transitional Re number and turbulent after that transitional Re number without any viscous dissipation according to the Reynolds number. The governing equations in Cartesian coordinates are:

Continuity equation:

$$
\frac{\partial}{\partial x_{i}}\left(\rho u_{i}\right)=0
$$

Equation of momentum:

$$
\begin{aligned}
& \rho \frac{\partial}{\partial x_{i}}\left(u_{i} u_{j}\right)=-\frac{\partial p}{\partial x_{j}}+ \\
& \frac{\partial}{\partial x_{i}}\left[\mu\left(\frac{\partial u_{i}}{\partial x_{j}}+\frac{\partial u_{j}}{\partial x_{i}}-\frac{2}{3} \delta_{i j} \frac{\partial u_{k}}{\partial x_{k}}\right)\right]+\frac{\partial}{\partial x_{i}}\left(-\rho \overline{u_{i}^{\prime} u_{j}^{\prime}}\right)
\end{aligned}
$$

where

$$
-\rho \overline{u_{i}^{\prime} u_{j}^{\prime}}=\mu_{t}\left(\frac{\partial u_{i}}{\partial x_{j}}+\frac{\partial u_{j}}{\partial x_{i}}\right)-\frac{2}{3}\left(\rho k+\mu_{t} \frac{\partial u_{k}}{\partial x_{k}}\right) \delta_{i j}
$$

Equation of energy:

$$
\frac{\partial}{\partial \mathrm{x}_{\mathrm{i}}}\left[\mathrm{u}_{\mathrm{i}}(\rho \mathrm{E}+\mathrm{p})\right]=\frac{\partial}{\partial \mathrm{x}_{\mathrm{i}}}\left(\mathrm{k}_{\mathrm{eff}} \frac{\partial \mathrm{T}}{\partial \mathrm{x}_{\mathrm{i}}}\right)
$$

where $\mathrm{E}$ is the total energy [W] and $\mathrm{k}_{\mathrm{eff}}$ is the effective thermal conductivity $\left(\mathrm{k}+\mathrm{k}_{\mathrm{t}}\right.$, where $\mathrm{k}_{\mathrm{t}}$ is the turbulent thermal conductivity, defined according to the turbulent model being used). The RNG $\mathrm{k}-\varepsilon$ turbulence model is defined to solve the conservation equations (FLUENT 6.2 User's Guide, 2004).

\section{Parameter Definition}

The characteristic and non-dimensional parameters used are defined as follows:

$\mathrm{R}_{\mathrm{e}}=\frac{\rho \mathrm{pD}_{\mathrm{e}}}{\mu}$

where $u$ is the inlet air velocity $[\mathrm{m} / \mathrm{s}], D_{e}$ is the hydraulic diameter of the fin entrance $[\mathrm{m}], \mu$ is the viscosity of air [Pa.s] and $\rho$ is the air density $\left[\mathrm{kg} / \mathrm{m}^{3}\right]$. The heat transfer coefficient $\mathrm{h}$ is obtained from the heat transfer rate $\mathrm{Q}$ and the log-mean temperature difference (LMTD).

$$
\mathrm{h}=\frac{\mathrm{Q}}{\eta_{0} \mathrm{~A} \Delta \mathrm{T}_{\mathrm{LMTD}}}
$$

Here $A$ is the area $\left[\mathrm{m}^{2}\right], \eta_{0}$ is the surface efficiency, and the log-mean temperature difference is given as follows: 


$$
\Delta \mathrm{T}_{\mathrm{LMTD}}=\frac{\left(\mathrm{T}_{\mathrm{W}}-\mathrm{T}_{\text {in }}\right)-\left(\mathrm{T}_{\mathrm{W}}-\mathrm{T}_{\text {out }}\right)}{\operatorname{In}\left[\frac{\left(\mathrm{T}_{\mathrm{W}}-\mathrm{T}_{\text {in }}\right)}{\left(\mathrm{T}_{\mathrm{W}}-\mathrm{T}_{\text {out }}\right)}\right]}
$$

The surface effectiveness $\eta_{\mathrm{a}}$ and the fin efficiency $\eta_{\mathrm{f}}$ for the dry surface of wavy fins are defined as [Yang and Tao, 1998]:

$$
\begin{aligned}
& \eta_{\mathrm{a}}=1-\frac{\mathrm{A}_{\mathrm{f}}}{\mathrm{A}_{0}}\left(1-\eta_{\mathrm{f}}\right) \\
& \eta_{\mathrm{f}}=\frac{\tanh \left(\mathrm{m}^{\prime} \mathrm{l}^{\prime}\right)}{\mathrm{m}^{\prime} \mathrm{l}^{\prime}}
\end{aligned}
$$

where $A_{f}$ is the fin surface area $\left[\mathrm{m}^{2}\right]$ and $A_{0}$ is the total air side heat transfer surface area $\left[\mathrm{m}^{2}\right]$, $\mathrm{m}^{\prime}=\sqrt{\frac{2 \mathrm{~h}}{\mathrm{k}_{\mathrm{f}} \delta}}$ and $\mathrm{l}^{\prime}=\frac{\mathrm{F}_{\mathrm{h}}}{2}$.

The heat transfer coefficient (h) can be obtained by iterative calculation from Equations (6) to (9). Therefore, the fin efficiency depends on the heat transfer coefficient, fin thickness and fin height.

The Colburn factor $(j)$ is used to describe the heat transfer performance.

$$
j=\frac{\mathrm{h}}{\rho \mathrm{uC}_{\mathrm{p}}} \mathrm{pr}^{\frac{2}{3}}
$$

where $C_{P}$ is the specific heat of the fluid $[\mathrm{J} /(\mathrm{kg} \cdot \mathrm{K})]$ and Pr is the Prandtl number. The friction factor $(f)$ is used to describe the pressure loss characteristics (Kays and London, 1984).

$$
f=\left(\frac{\mathrm{A}_{\mathrm{c}}}{\mathrm{A}_{0}}\right)\left(\frac{2 \Delta \mathrm{p}}{\rho \mathrm{u}^{2}}-\mathrm{k}_{\mathrm{c}}-\mathrm{k}_{\mathrm{e}}\right)
$$

Here $A_{c}$ is the minimum free-low area for the air side and $\Delta \mathrm{P}$ is the pressure drop in the flow direction $[\mathrm{Pa}]$. According to the geometric parameters of the heat exchanger and the graph, $\mathrm{k}_{\mathrm{c}}$ and $\mathrm{k}_{\mathrm{e}}$ are 0.4 and 0.2 , respectively.

\section{CFD Simulation Method}

The governing equations and the boundary conditions of the WFFT heat exchanger are solved in the three-dimensional system by the finite volume method for the thermal and fluid dynamics analysis.

\section{Model Development of Neural Network}

This paper develops a neural network to estimate the $j$ and $f$ factors in terms of the geometrical parameters in WFFT heat exchangers. Input and output parameters must be defined in the first step. Output parameters of the neural network are known and they depend on the aim of the research at hand. An important point to be taken into account is that the input parameters are chosen so as to facilitate the calculation of the neural network output data. With this consideration, $\mathrm{F}_{\mathrm{p}}, \mathrm{F}_{\mathrm{h}}, \mathrm{L}_{\mathrm{d}}, \mathrm{L}, \delta, 2 \mathrm{~A}$ and Re were chosen as the basis of the calculation. Neural network input variables were converted to nondimensional parameters by dividing each factor by the same dimensional factor and then powers of the input parameters are selected in order to normalize all of the input variables. Input variable are defined as follows:

$$
\begin{aligned}
& \text { input1 }=\operatorname{Re}^{0.1833} \\
& \text { input2 }=\left(\frac{F_{p}}{F_{h}}\right)^{-1.3836} \\
& \text { input3 }=\left(\frac{F_{p}}{\delta}\right)^{0.1287} \\
& \text { input4 }=\left(\frac{L_{d}}{L}\right)^{0.8967} \\
& \text { input5 }=\left(\frac{F_{p}}{2 A}\right)^{1.9583}
\end{aligned}
$$

Five input values are set by the geometrical parameter data and five input neurons are created in the input layer of the neural network structure corresponding to the input values. One output neuron is present in the output layer of neural network. Trial and error was used in order to find the hidden layer size and the number of neurons. Increasing the number of hidden neurons increases the accuracy of the network to a point; however, the accuracy declines thereafter, allowing the optimum number of neurons to be specified (Krose and Smagt, 1996). 84 and 22 sets of data are utilized in the training process and testing and for validation of the network, respectively. Here, five neurons were found to be optimum for the hidden layer.

Cascade back propagation is selected in order to train the neural network in this study. This training 
method is more accurate than feed forward back propagation and a more appropriate answer is obtained.

Each layer of the neural network should have a transfer function to produce the neuron output values. Here, a combination of linear and tangentsigmoid functions is employed and these two types of functions apply to the output and hidden layers, respectively. The latter function is expressed as follows (Demuth et al, 2007):

Tangent $-\operatorname{Sigmoid}(\mathrm{z})=\frac{2}{1+\mathrm{e}^{-2 \mathrm{z}}}-1$

All the neural network training was carried out with the MATLAB toolbox. A typical scheme for a neural network can be seen in Fig. 5.

\section{NUMERICAL RESULTS AND DISCUSSION}

\section{Model Validation}

The first 11 of the 15 wavy fin models in this work have the same geometries and operating conditions as the wavy fins tested experimentally in Dong et al. (2007b), with which the present CFD simulation results are compared. The other four models investigate the influences of fin thickness and wave amplitude on the characteristics of WFFT heat exchangers.

The experimental observations and data for the flow regime transition from laminar to turbulence in the triangular sinusoidal wavy fin channel are not so well defined. In this fin, the transition to turbulence occurs at lower Reynolds numbers than in a plain fin-and-flat tube heat exchanger. Therefore, in the present study, two laminar and turbulent regimes are computed for all models in order to verify the transition range of $\mathrm{Re}$ and the appropriate regime. The results show that only the numerical results of the laminar regime exhibit a good coincidence with the empirical data for all models at $\operatorname{Re}<1900$. The result curves of the regime decrease more strongly than the experimental curves with increasing Re. According to the model configurations, the transition regime occurs in the 1900 to 2100 range of Re.

It has been shown by Tian et al. (2009) that the (RNG) $\mathrm{k}-\varepsilon$ model provides a more satisfactory description of the flow pattern and the turbulence properties than standard k- $\varepsilon$ in the wavy fin-and-tube heat exchangers. Moreover, the (RNG) $\mathrm{k}-\varepsilon$ model requires less computational time in comparison with realizable $\mathrm{k}-\varepsilon$ and $\mathrm{k}-\omega$ models. Computational results with the (RNG) $k-\varepsilon$ model show a good agreement with the experimental results obtained by Dong et al. (2007b). The average deviations of the $j$ and $f$ factors for the RNG $\mathrm{k}-\varepsilon$ model are $3.8 \%$ and $8.2 \%$, respectively. Thus, the (RNG) $\mathrm{k}-\varepsilon$ turbulent model was chosen to study the effect of geometrical parameters on the performance of wavy fin-and-flat tube heat exchangers in the current work. A comparison of the numerical and experimental results of model 1 and 7 are provided in Figs. 6 and 7, respectively.

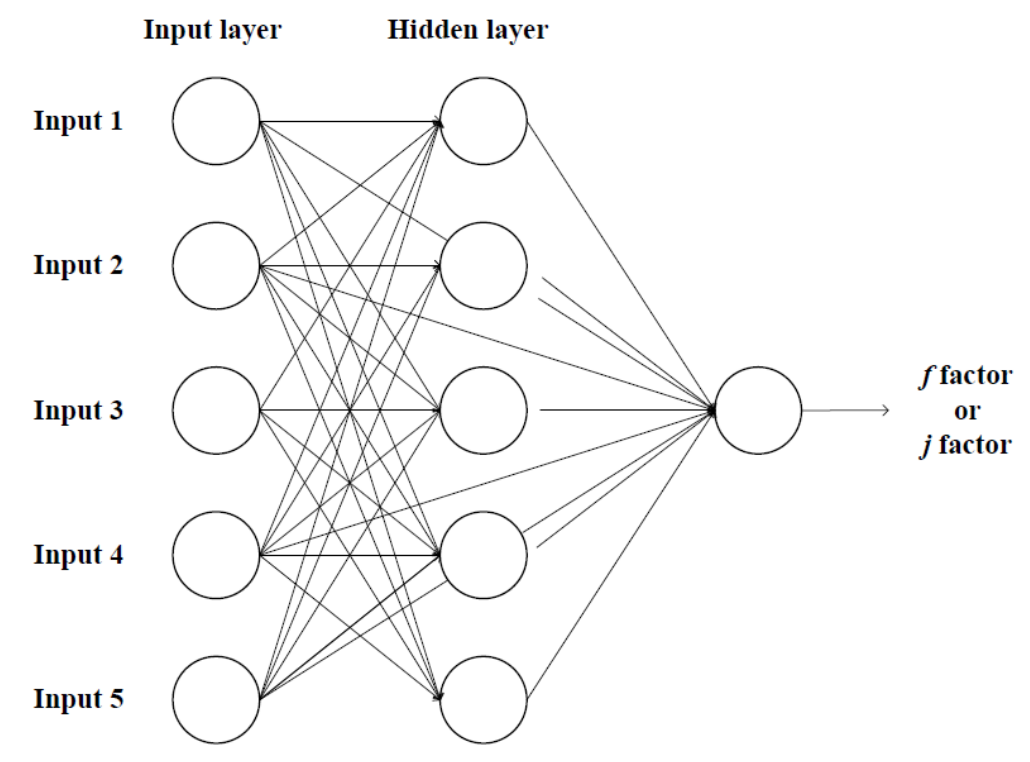

Figure 5: Typical scheme for a neural network. Inputs 1-5 are calculated from Equations (12)-(16) 


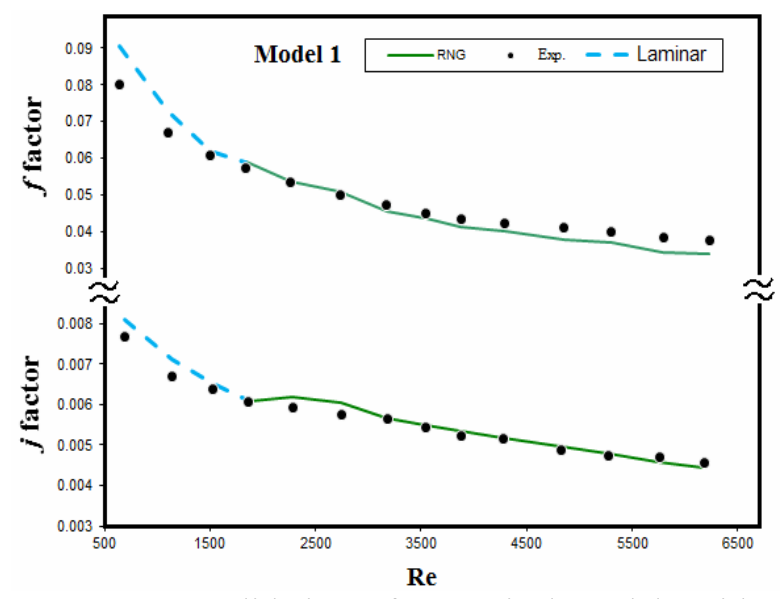

Figure 6: Validation of numerical models with experimental results (Model 1)

\section{$j$ and $f$ Factors Versus Reynolds Number}

The effects of fin pitch $\left(\mathrm{F}_{\mathrm{p}}\right)$, fin height $\left(\mathrm{F}_{\mathrm{h}}\right)$, fin length $\left(F_{L}\right)$, fin thickness $(\delta)$, and wave amplitude (2A) on the air side performance of triangular sinusoidal WFFT heat exchangers are numerically simulated at the same wave length (L). The wave length of the examined wavy fins is $10.8 \mathrm{~mm}$. The air side heat transfer and friction characteristics of all tested models are determined by running computational fluid dynamics (CFD) code and they are presented in terms of the Colburn factor $(j)$ and friction factor (f), which are plotted versus the Reynolds number based on the fin entrance hydraulic diameter (Dong et al., 2007b).

Figs. 8-15 present the effects of fin pitch, fin height, fin length, fin thickness, and wave amplitude on the performance of WFFT heat exchangers having different geometric parameters. These figures confirm that the parameters of wavy fins have a

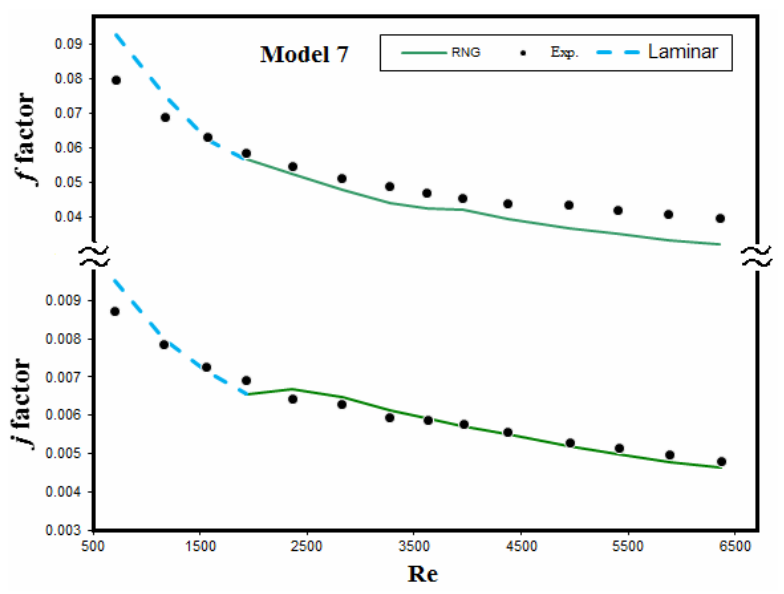

Figure 7: Validation of numerical models with experimental results (Model 7)

considerable effect on the $j$ and $f$ factors as a function of Re, as discussed in the following:

- The $j$ and $f$ factors increase with increasing fin pitch at constant other geometrical parameters and $\mathrm{Re}$ number. The velocity vectors on the specific surface are presented in Fig. 8 at the same axial location $(\mathrm{z}=20 \mathrm{~mm})$ for a flow rate with $\mathrm{Re}=5450$. With increasing fin pitch, the secondary flow is increased, so this event causes the convective mixing, heat and momentum to increase considerably from the transport phenomena view point. The temperature distributions of the fluid for the three models 7, 8, and 9 with different fin pitches are shown in Fig. 9. These temperature contours are presented for four different cross sections vertical to the $\mathrm{z}$ coordinate axis $(\mathrm{z}=10$, 20,30 , and $40 \mathrm{~mm}$ ), where the air inlet velocity equals $5 \mathrm{~m} / \mathrm{s}$. A high temperature gradient and a well mixed air flow occur in the corrugated channel at the same Re numbers upon increasing the fin pitch. Models 3, 6 and 9 have the highest $j$ and $f$ factors, as shown in Fig. 10.

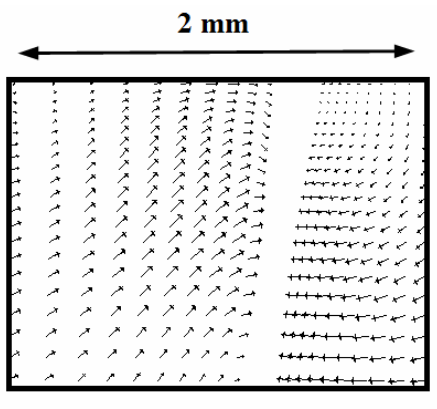

(a)

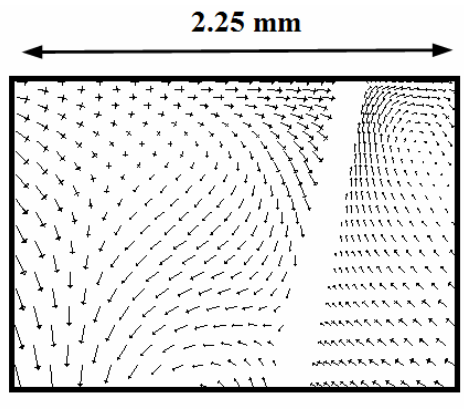

(b)

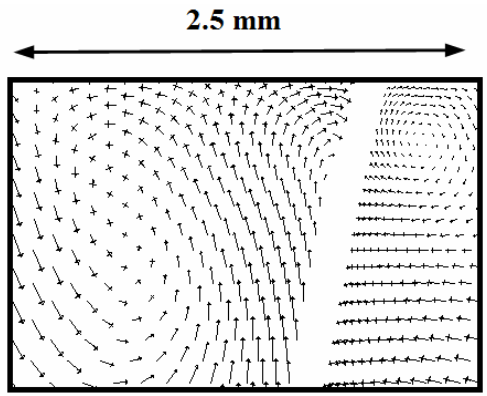

(c)

Figure 8: Velocity vectors for three wavy channels with different fin pitches $\left(\mathrm{F}_{\mathrm{p}}\right)$ on the specific surface, with $R e=5450,(a): F_{p}=2 \mathrm{~mm}(b): F_{p}=2.25 \mathrm{~mm}(c): F_{p}=2.5 \mathrm{~mm}$. 

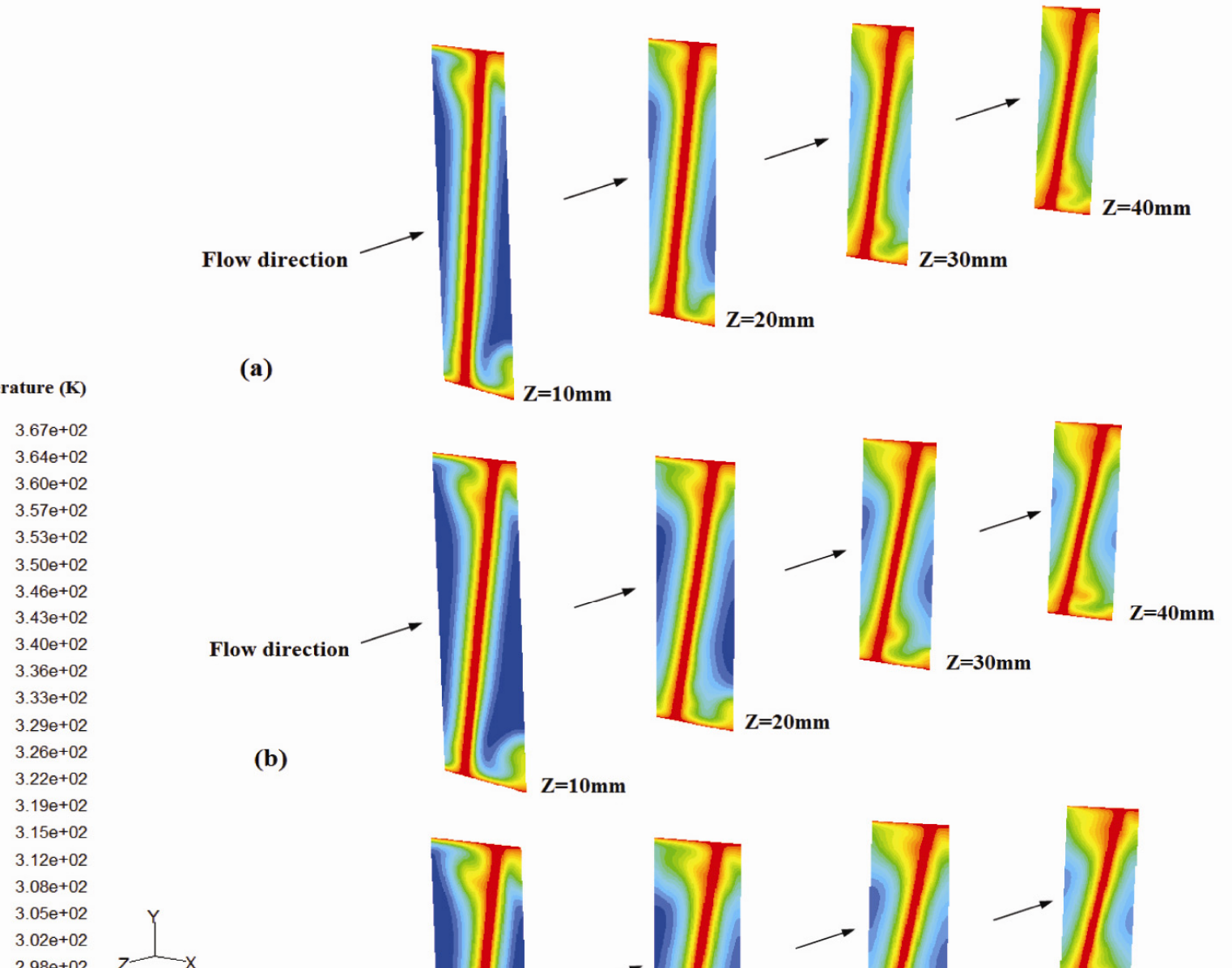

(c)

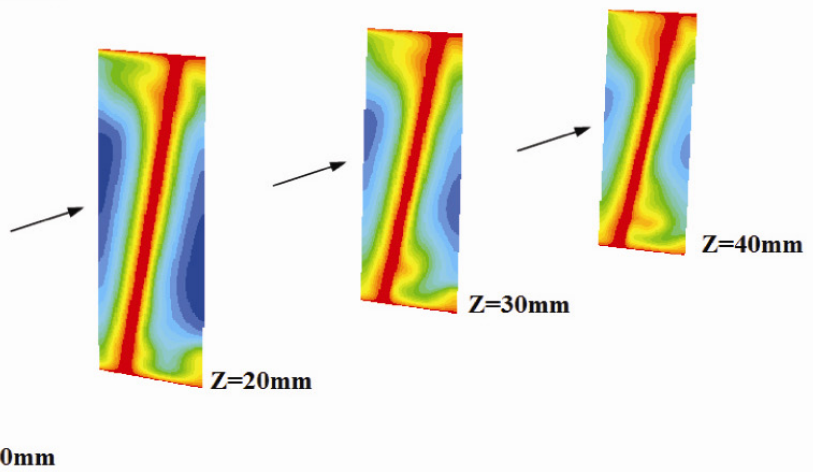

Figure 9: Temperature distribution for three wavy channels with the different fin pitches $\left(\mathrm{F}_{\mathrm{p}}\right)$ on four different cross sections $(z=10,20,30$ and $40 \mathrm{~mm})$, with Uin $=5 \mathrm{~m} / \mathrm{s}$, (a) $F_{p}=2 \mathrm{~mm}$; (b) $F_{p}=2.25 \mathrm{~mm}$; (c) $F_{p}=2.5 \mathrm{~mm}$.

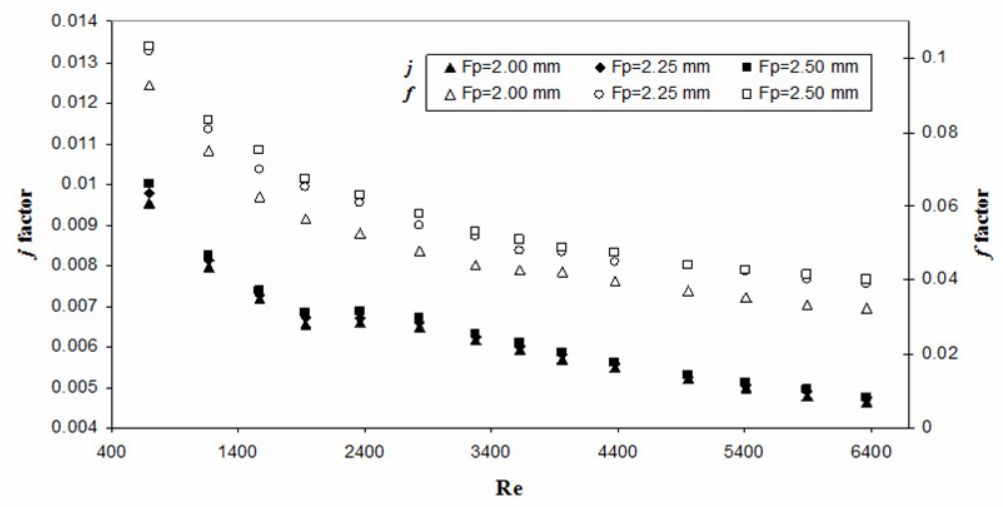

Figure 10: Effect of fin pitch $\left(\mathrm{F}_{\mathrm{p}}\right)$ on the $j$ and $f$ factors 
- The fin height has a significant effect on the $j$ factor, whereas the influence of this parameter on the $f$ factor is not important. This can be confirmed from the results of Dong et al. (2007b) in their empirical investigation of wavy fin-and-flat tube heat exchangers. This reflects the fact that the dependence of the pressure drop of the air flow on flow path length is higher than for the cross section because the variation of fin pitch in the models is small, making the change of the $f$ factor less important. Fig. 11 shows the temperature distribution for models 7,10 , and 11 with different fin heights on the flow direction surfaces for a $5 \mathrm{~m} / \mathrm{s}$ air inlet velocity. Increasing the fin height decreases the average outlet temperature of the channel, which in turn abates the log-mean temperature difference and enhances the heat transfer coefficient. The values of the $j$ factor increase with increasing heat transfer coefficient at constant Reynolds and Prandtl numbers (Eq. (10)). Model 11 has the largest $j$ factor in comparison with models 7 and 10 , as depicted in Fig. 12.

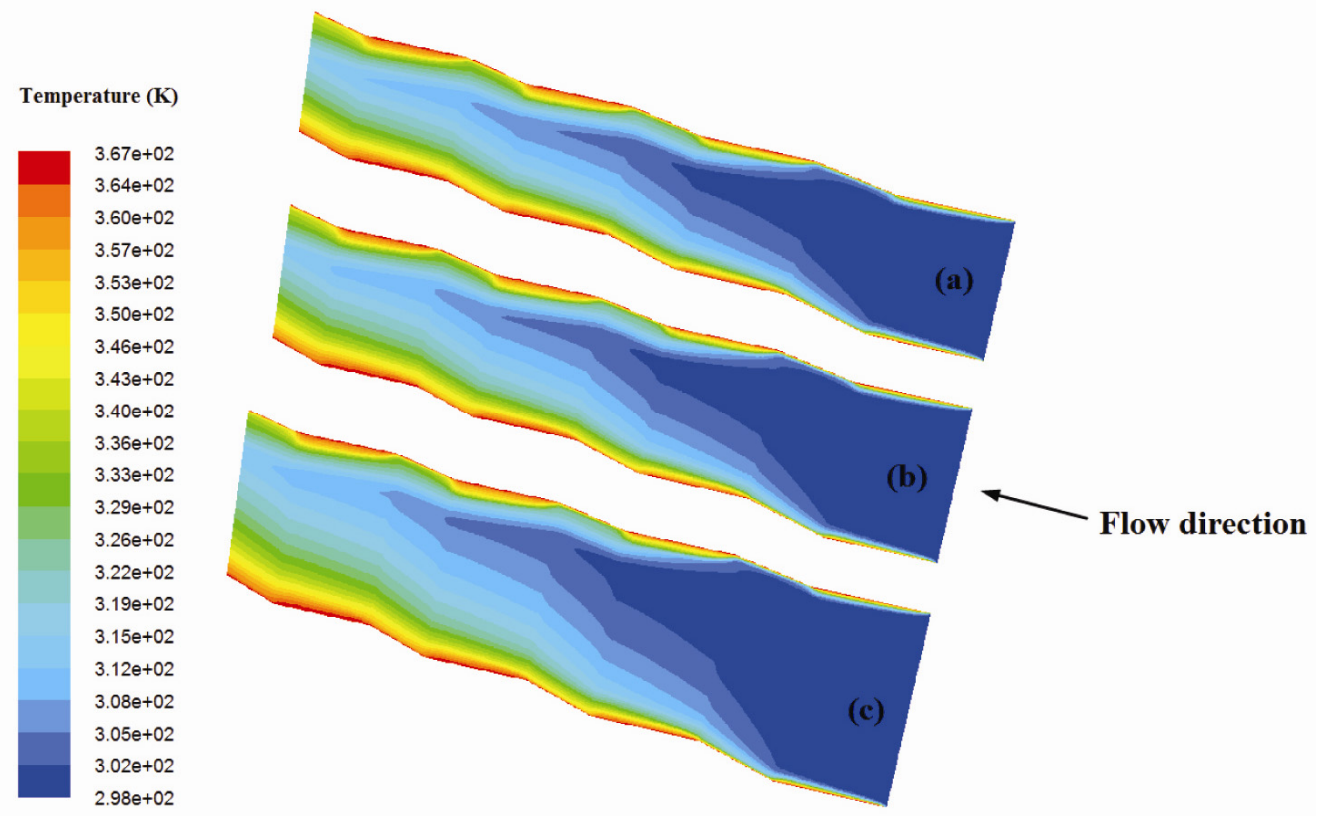

Figure 11: Temperature distribution for three wavy channels with different fin heights $\left(\mathrm{F}_{\mathrm{h}}\right)$, on the flow direction surface, with Uin $=5 \mathrm{~m} / \mathrm{s}$, (a) $F_{h}=7 \mathrm{~mm}$; (b) $F_{h}=8 \mathrm{~mm}$; (c) $F_{h}=10 \mathrm{~mm}$.

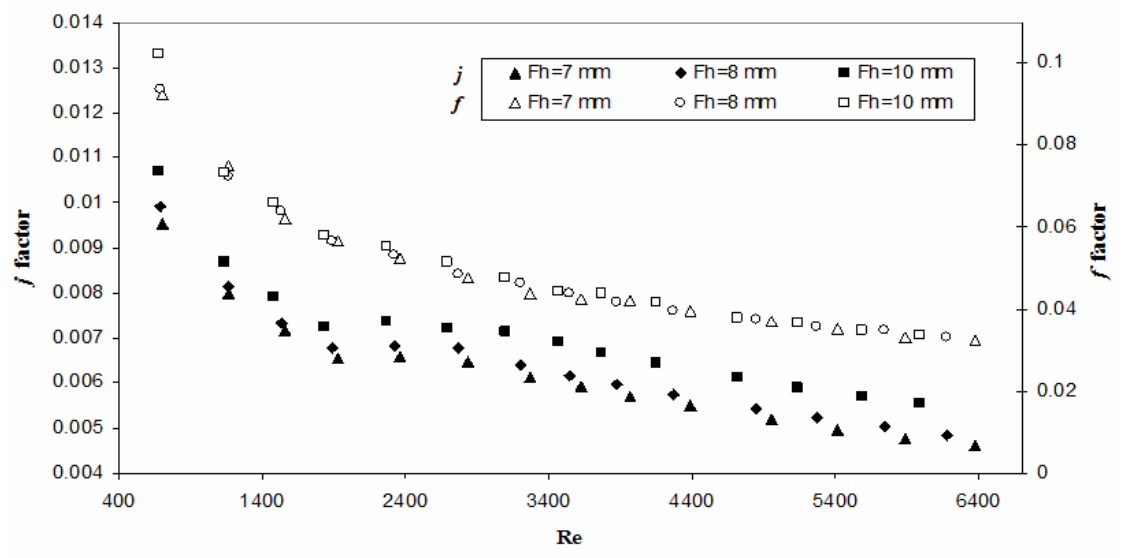

Figure 12: Effect of fin height $\left(\mathrm{F}_{\mathrm{h}}\right)$ on the $j$ and $f$ factors 
- In contrast to the two previous parameters, fin length has an inverse effect on air side performance of WFFT heat exchangers, the $j$ and $f$ factors decreasing with increasing fin length. Fig. 13 presents the temperature distribution for models 1, 4, and 10 with different fin lengths on the surface in flow direction for a $5 \mathrm{~m} / \mathrm{s}$ air inlet velocity. Development of the fluid flow and reduction of the temperature gradient in the cross section decrease the heat transfer coefficient by expansion of the channel length and the heat transfer area; as a result, the fin efficiency $\left(\eta_{\mathrm{f}}\right)$ and $j$ factor drop (Eqs. (9) and (10)). Fig. 14 shows that the $j$ factor has the lowest value in model 1 in comparison to models 4 and 10. In addition, model 4 is lower than model 10 for the same Re.

- As the fin thickness is decreased, the $j$ factor is augmented because heat resistance between the two sides of the fin is lower for this case, whereas the $f$ factor is not changed visibly since the channel configurations are the same for the fluid flow stream in models 7, 12 and, 13, as plotted in Fig. 15.

- Simulation results illustrate the fact that larger $j$ factor and $f$ factor values are obtained as the wave amplitude is increased and also, the effect of this parameter on the $f$ factor is higher than for the $j$ factor. This result agrees with conclusions of Zhang et al. (2004), Manglik et al. (2005), Metwally and Manglik (2004), and Dong et al. (2010), who utilized a numerical solution for a wide range of Reynolds numbers. This CFD result indicates that an optimization should be made of the $j$ and $f$ factors versus wavy amplitude for the best performance of WFFT heat exchangers since this parameter is one of the most important factors in the design of WFFT heat exchangers. Fig. 16 shows that model 14 has larger $j$ factor and $f$ factor values than models 1 and 15 .

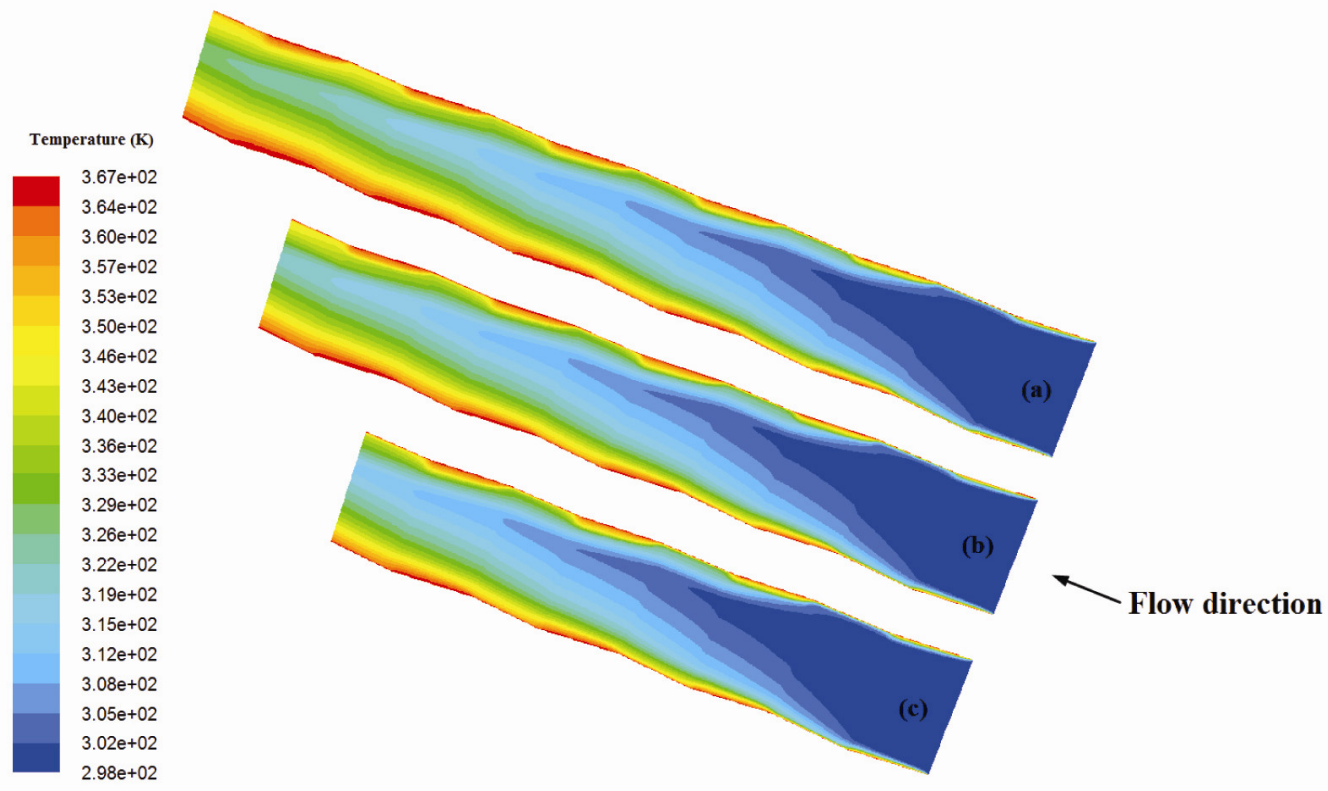

Figure 13: Temperature distribution for three wavy channels with the different fin lengths $\left(\mathrm{L}_{\mathrm{d}}\right)$, on flow direction surface, for $\operatorname{Uin}=5 \mathrm{~m} / \mathrm{s}$, (a) $\mathrm{L}_{\mathrm{d}}=65 \mathrm{~mm}$; (b) $\mathrm{L}_{\mathrm{d}}=53 \mathrm{~mm}$; (c) $\mathrm{L}_{\mathrm{d}}=43 \mathrm{~mm}$.

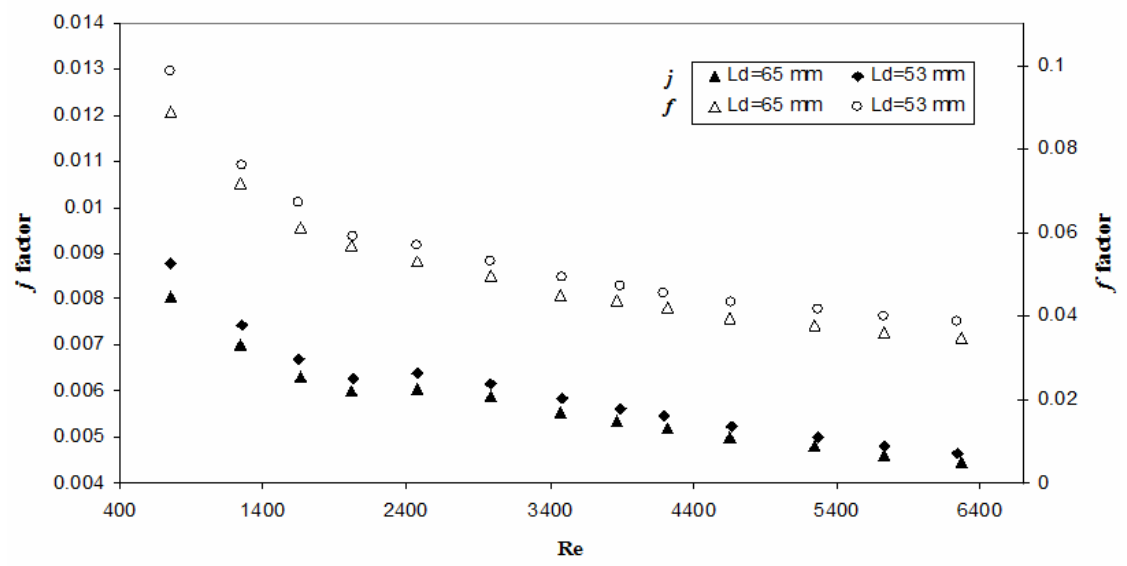

Figure 14: Effect of fin length $\left(\mathrm{L}_{\mathrm{d}}\right)$ on the $j$ and $f$ factors 


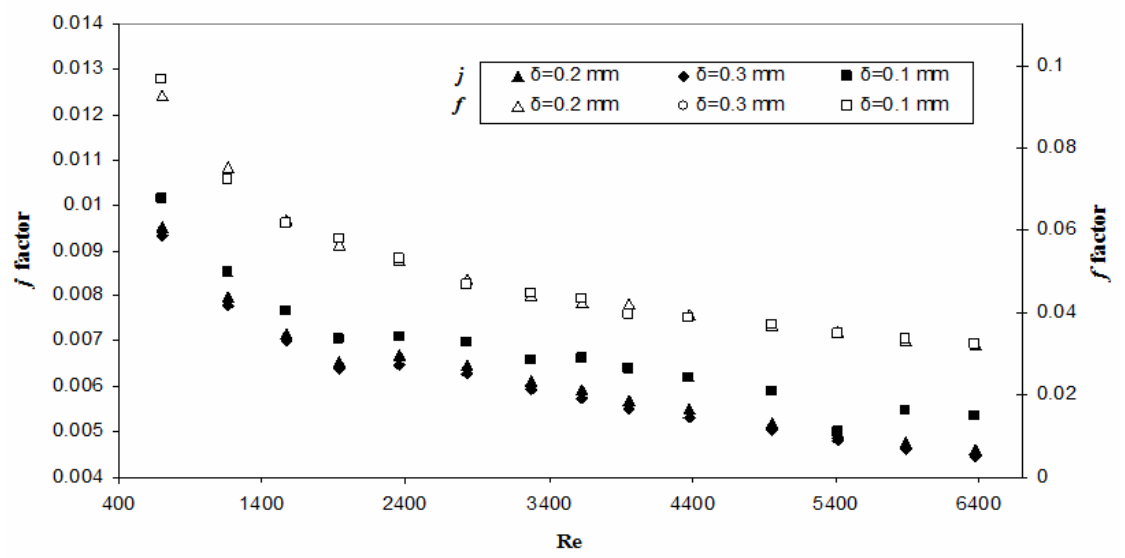

Figure 15: Effect of fin thickness $(\delta)$ on the $j$ and $f$ factors

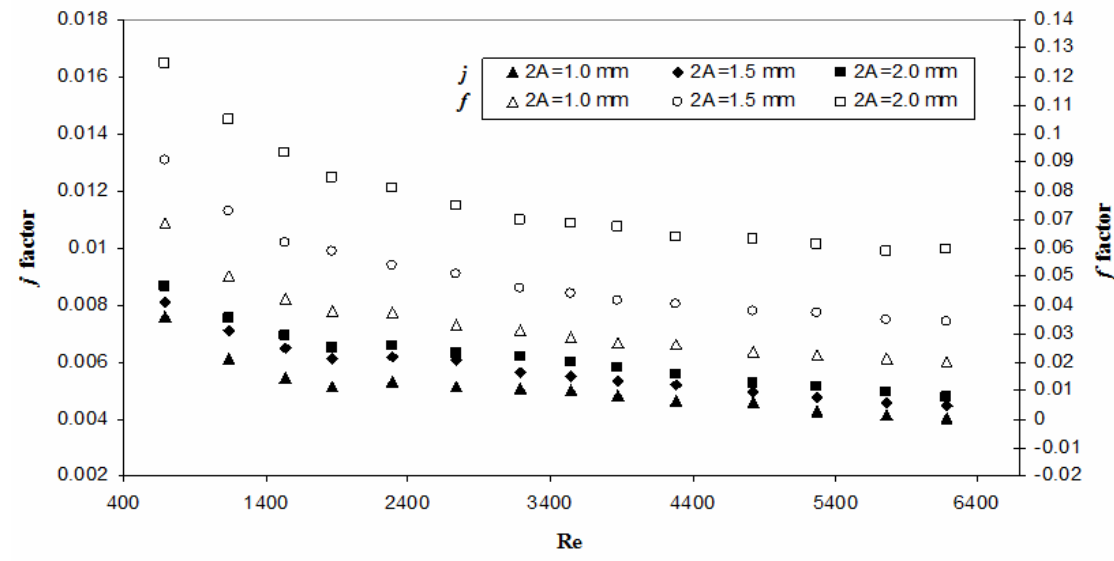

Figure 16: Effect of wave amplitude (2A) on the $j$ and $f$ factors

The results obtained in this 3D-CFD simulation study show good agreement with the experimental studies conducted by Dong et al. (2007). The accuracy of the calculations of the $j$ factor and $f$ factor are evaluated by the absolute average relative deviations which are $3.8 \%$ and $8.2 \%$, respectively. This work indicates the validity of CFD simulations in heat exchanger design.

\section{Neural Network Model}

In the design of the artificial neural network, we made use of a combination of linear and tangentsigmoid functions because this combination is capable of solving most complicated problems (Demuth et al, 2007). The tangent-sigmoid function acts like the hyperbolic tangent function, which gives very similar numerical results, but the tangent-sigmoid takes the advantage of higher speed in the training process. The results obtained in this study indicate that this function is much more accurate than any other.

Apparently, the logarithmic sigmoid function is suitable for the output layers, considering that each output neuron acts in the range of $0-1$ and that the sigmoid response function falls in the same range. It is used in most neural networks because of its inherent properties. But in our investigation, the linear function was applied to the output layer for the results, proving that the sigmoid function was not able to show as an appropriate answer as the linear one. The logarithmic sigmoid function with the output interval $(0,1)$ is written as follows (Demuth et al., 2007):

$$
\log -\operatorname{Sigmoid}(\mathrm{z})=\frac{1}{1+\mathrm{e}^{-\mathrm{z}}}
$$

It is of extreme importance to determine the training data limitations because the neural network 
extrapolates unfavorably. However, it does give excellent interpolations provided that it is trained correctly and suitably. Table 3 shows the upper and lower limits for the neural network training data. These ranges are a mid conservative 90 percent of the original ones to guarantee the performance for the neural network. Therefore, it is necessary to check these limitations whenever any data set is introduced to the neural network in order to perform simulation and estimate the results. Using 15 sets of test data ensures the response accuracy for the neural network within the limits. The weights of every layer of $j$ and $f$ factors are given in Tables 4 and 5, respectively.

The magnitudes of the errors of $j$ and $f$ factors are less than $1.3 \%$ and $1 \%$, respectively, compared to real values and the CFD simulation, as shown in Figs. 17 and 18 for models 1 and 7. These errors indicate appropriate accuracy of the established neural network. This precision is obtained due to the high learning ability of the neural network, making the network capable of adapting to any network data.

Table 3: Upper and lower limits for input data.

\begin{tabular}{|c|c|c|}
\hline properties & minimum & maximum \\
\hline Input1 & 3.29 & 5.10 \\
Input2 & 4.99 & 9.27 \\
Input3 & 1.34 & 1.38 \\
Input4 & 3.45 & 4.99 \\
Input5 & 1.75 & 2.71 \\
\hline
\end{tabular}

Table 4: Weights of every layer of the neural network related to the $\boldsymbol{j}$ factor

\begin{tabular}{|c|c|c|c|c|c|c|c|}
\hline & & \multicolumn{6}{|c|}{ Weights into hidden layer } \\
\hline \multicolumn{2}{|c|}{ input data } & input 1 & input 2 & input 3 & input 4 & input 5 & bias \\
\hline \multicolumn{2}{|c|}{ neuron 1 of hidden layer } & -0.95857 & 0.73149 & -29.7179 & 1.7702 & -0.44193 & 37.722 \\
\hline \multicolumn{2}{|c|}{ neuron 2 of hidden layer } & 1.0244 & -0.5456 & 23.2378 & 0.64045 & -1.3261 & -33.172 \\
\hline \multicolumn{2}{|c|}{ neuron 3 of hidden layer } & -0.8468 & -0.72236 & -36.0165 & -0.29603 & 0.64766 & 57.982 \\
\hline \multicolumn{2}{|c|}{ neuron 4 of hidden layer } & -0.69284 & 0.59889 & -5.5477 & -0.00129 & 2.0826 & 1.6009 \\
\hline \multicolumn{2}{|c|}{ neuron 5 of hidden layer } & 1.1689 & -0.43225 & -63.9673 & -0.68955 & 0.40129 & 89.3443 \\
\hline \multicolumn{6}{|c|}{ Weights into output layer } & bias & \\
\hline input 1 & -0.0029427 & \multicolumn{3}{|c|}{ neuron1 of hidden layer } & 0.016015 & 0.10912 & \\
\hline input 2 & 0.0005836 & \multicolumn{3}{|c|}{ neuron 2 of hidden layer } & 0.001313 & & \\
\hline input 3 & -0.08379 & \multicolumn{3}{|c|}{ neuron 3 of hidden layer } & $-1.53 \mathrm{E}-05$ & & \\
\hline input 4 & -0.0010377 & \multicolumn{3}{|c|}{ neuron 4 of hidden layer } & -0.00089 & & \\
\hline input 5 & 0.0045085 & \multicolumn{3}{|c|}{ neuron 5 of hidden layer } & -0.00117 & & \\
\hline
\end{tabular}

Table 5: Weights of every layer of the neural network related to the $f$ factor

\begin{tabular}{|c|c|c|c|c|c|c|c|}
\hline & & \multicolumn{6}{|c|}{ Weights into hidden layer } \\
\hline \multicolumn{2}{|c|}{ input data } & input 1 & input 2 & input 3 & input 4 & input 5 & bias \\
\hline \multicolumn{2}{|c|}{ neuron1 of hidden layer } & -0.29926 & -0.05695 & -29.6061 & 1.4768 & -1.5594 & 45.1071 \\
\hline \multicolumn{2}{|c|}{ neuron 2 of hidden layer } & 1.2942 & -1.0886 & -46.4788 & 0.36945 & 1.8128 & 58.8416 \\
\hline \multicolumn{2}{|c|}{ neuron 3 of hidden layer } & -1.0869 & -0.35335 & -59.6438 & -0.39407 & 1.7274 & 86.2497 \\
\hline \multicolumn{2}{|c|}{ neuron 4 of hidden layer } & -0.00393 & -0.74441 & 33.6488 & 1.2558 & -2.5865 & -41.3778 \\
\hline \multicolumn{2}{|c|}{ neuron 5 of hidden layer } & 1.7206 & 0.36737 & -13.9442 & 0.1091 & 1.4598 & 7.4106 \\
\hline \multicolumn{6}{|c|}{ Weights into output layer } & bias & \\
\hline input 1 & -0.00607 & \multicolumn{3}{|c|}{ neuron1 of hidden layer } & -0.82407 & -0.33778 & \\
\hline input 2 & 0.005145 & \multicolumn{3}{|c|}{ neuron 2 of hidden layer } & 0.002752 & & \\
\hline input 3 & 0.90444 & \multicolumn{3}{|c|}{ neuron 3 of hidden layer } & 0.013715 & & \\
\hline input 4 & 0.008995 & \multicolumn{3}{|c|}{ neuron 4 of hidden layer } & -0.00766 & & \\
\hline input 5 & -0.02242 & \multicolumn{3}{|c|}{ neuron 5 of hidden layer } & -0.01638 & & \\
\hline
\end{tabular}




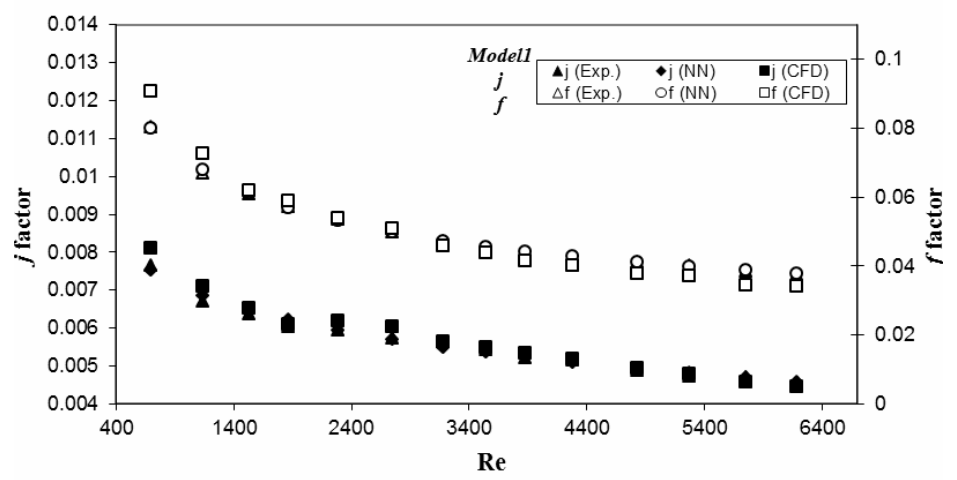

Figure 17: Comparison of the $j$ and $f$ factors from experiment, the neural network and the CFD simulation (Model 1)

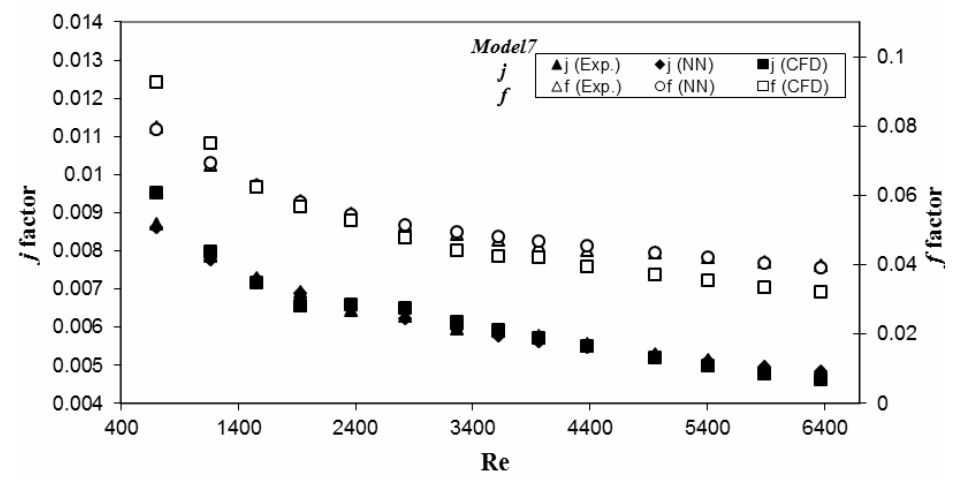

Figure 18: Comparison of the $j$ and $f$ factors from experiment, the neural network and the CFD simulation (Model 7)

\section{Correlations}

New correlations are proposed to predict the $j$ and $f$ factors based on experimental data from the literature (Dong et al., 2007b) for wavy fin-and-flat tube heat exchangers. Four geometrical parameters and the $\mathrm{Re}$ number provide well optimized correlations with absolute average relative deviations for the $j$ and $f$ factors of $3.22 \%$ and $3.68 \%$ from Equation (19) and average deviation from Equation (20) of $0.0022 \%$ and $-0.193 \%$, respectively.

$$
\operatorname{AARD}(\%)=\frac{1}{\mathrm{~N}}\left(\sum_{\mathrm{i}}^{\mathrm{N}}\left|\frac{\mathrm{Q}_{\text {cor }}-\mathrm{Q}_{\mathrm{exp}}}{\mathrm{Q}_{\exp }}\right|\right) \times 100 \%
$$

Average.Deviation $(\%)=$

$$
\frac{1}{\mathrm{~N}}\left(\sum_{\mathrm{i}}^{\mathrm{N}} \frac{\mathrm{Q}_{\text {cor }}-\mathrm{Q}_{\exp }}{\mathrm{Q}_{\exp }}\right) \times 100 \%
$$

The correlations of the $j$ and $f$ factors are presented as follows:

$$
\begin{aligned}
& j=0.0482 \mathrm{Re}^{-0.23725}\left(\frac{\mathrm{F}_{\mathrm{p}}}{\mathrm{F}_{\mathrm{h}}}\right)^{-0.1230}\left(\frac{\mathrm{L}_{\mathrm{d}}}{\mathrm{L}}\right)^{-0.21835} \\
& f=0.4006 \mathrm{Re}^{-0.28666}\left(\frac{\mathrm{F}_{\mathrm{p}}}{\mathrm{F}_{\mathrm{h}}}\right)^{-0.09879}\left(\frac{\mathrm{L}_{\mathrm{d}}}{\mathrm{L}}\right)^{0.072543}
\end{aligned}
$$

\section{CONCLUSIONS}

In this work, the behavior of the Colburn factor $(j)$ and the Fanning friction factor $(f)$ of wavy finand-flat tube (WFFT) heat exchangers is investigated numerically to determine the effects of geometrical parameters and the Reynolds number. The numerical calculations consist of two parts, the CFD simulation and the neural network model. According to the numerical results, the following conclusion can be made:

- For all models, the $j$ and $f$ factors decrease with increasing $\operatorname{Re}$ number in the range of Reynolds numbers tested (laminar and turbulent regimes). The 
CFD results demonstrate that the effect of each geometrical parameter on the WFFT heat exchangers' behavior is unique. For the same geometrical parameters and Re number, the $j$ and $f$ factors increase with increasing fin pitch in the models. The same result is true for fin height, but the effect of this parameter on the $f$ factor is very weak. Fin length and fin thickness have an inverse effect on the air side performance of WFFT heat exchangers. Therefore, an increase in fin length causes reduction of the $j$ and $f$ factors, while the effect of fin thickness on the $f$ factor is very low. One of the most prominent factors in the WFFT heat exchanger's performance is wave amplitude. Enlarging this parameter strongly intensifies the $j$ and $f$ factor values. The computational results have an appropriate accuracy in comparison with the experimental data. The accuracy of the calculations of the $j$ and $f$ factors is evaluated by the absolute average relative deviations, which are $3.8 \%$ and $8.2 \%$, respectively. This work indicates that the generation of the actual computational domain, intensification of the grid system near the sensitive transport phenomena zones and proper definition of the boundary conditions can significantly improve CFD results for heat exchanger design.

- The accuracy of the neural network is quite high, with less than $1.3 \%$ and $1 \%$ error between real and simulated $j$ and $f$ factors, respectively. This study shows the ability of a neural network to predict the heat transfer and pressure drop behavior in WFFT heat exchangers based on geometrical parameters and the Re number. It is important that the correct input parameters be selected in order to achieve a precise response; therefore, normalized dimensionless factors were chosen to create and to design the neural network.

- Two correlations are proposed based on an empirical test from literature. The correlations presented can predict the $j$ and $f$ factors for WFFT heat exchangers with good accuracy using the Re number, fin pitch, fin height, fin length and wave length, with AARD of $3.22 \%$ and $3.68 \%$ for the $j$ and $f$ factors.

The CFD simulation can be used to design and estimate the required fluid dynamic parameters with their boundary conditions, but the neural network only works with well defined factors and cannot easily be adjusted to a new situation. However, the neural network can give the appropriate answers in special and certain conditions if experimental results are available in order to train and validate the network.

\section{NOMENCLATURE}

A A $\quad$ area $\quad \mathrm{m}^{2}$

$\mathrm{A}_{\mathrm{c}} \quad$ minimum free-low area for air side

$\mathrm{A}_{0} \quad$ total air side heat transfer surface area

$\mathrm{A}_{\mathrm{f}} \quad$ fin surface area

$\mathrm{C}_{\mathrm{p}} \quad$ specific heat of the fluid

$\mathrm{De} \quad 4 \mathrm{AcL} / \mathrm{A}_{0}$, hydraulic diameter

E total energy

$\mathrm{F}_{\mathrm{h}} \quad$ fin height

$\mathrm{F}_{\mathrm{p}} \quad$ fin pitch

$f$ fanning friction factor

h heat transfer coefficient

$j \quad$ Colburn factor

$\mathrm{k}$ turbulence kinetic energy

L wavy fin wave length

$\mathrm{L}_{\mathrm{d}} \quad$ wavy fin length

$\mathrm{P} \quad$ pressure

$\Delta \mathrm{p} \quad$ pressure drop in flow direction

Pr Prandtl number

Q heat transfer rate

$\mathrm{Re} \quad$ air side Reynolds number based on fin entrance diameter

$\mathrm{T}$ temperature

$\mathrm{u}_{\mathrm{i}}, \mathrm{u}_{\mathrm{j}}, \mathrm{u}_{\mathrm{k}}$ velocity components

$\mathrm{x}_{\mathrm{i}}, \mathrm{x}_{\mathrm{j}}, \mathrm{x}_{\mathrm{k}}$ cartesian coordinates

\section{Greek Symbols}

$\begin{array}{ll}\mu & \text { dynamic viscosity } \\ \rho & \text { density } \\ \varepsilon & \text { turbulent energy dissipation } \\ & \text { rate } \\ \delta & \text { fin thickness } \\ \eta_{\mathrm{a}} & \text { air side heat transfer surface } \\ & \text { effectiveness } \\ \eta_{\mathrm{f}} & \text { fin efficiency } \\ \eta_{0} & \text { surface efficiency }\end{array}$

$\mathrm{kg} / \mathrm{m} . \mathrm{s}$ $\mathrm{kg} / \mathrm{m}^{3}$ $\mathrm{m}^{2} / \mathrm{s}^{3}$

\section{Subscripts}

$\begin{array}{ll}\text { in } & \text { inlet } \\ \text { out } & \text { outlet } \\ \text { w } & \text { tube wall }\end{array}$

\section{REFERENCES}

Demuth, H., Beale, M., Hagan, M., Neural network toolbox 5 user's Guide of MATLAB. MathWorks, Inc. (2007).

Dong, J., Chen, J., Chen, Z., Zhang, W., Zhou, Y., Heat transfer and pressure drop correlations for 
the multi-louvered fin compact heat exchangers. Energ. Convers. Manage., 48, 1506-1515 (2007a).

Dong, J., Chen, J., Chen, Z., Zhou, Z., Zhang W., Heat transfer and pressure drop correlations for the wavy fin and flat tube heat exchangers. Appl. Therm. Eng., 27, 2066-2073 (2007b).

Dong, J., Chen, J., Chen, Z., Zhou, Y., Air-side thermal hydraulic performance of offset strip fin aluminum heat exchangers. Appl. Therm. Eng., 27, 306-313 (2007c).

Dong, J., Chen, J., Zhang, W., Hu, J., Experimental and numerical investigation of thermal-hydraulic performance in wavy fin-and-flat tube heat exchangers. Appl. Therm. Eng., 30, 1377-1386 (2010).

Erek, A., Özerdem, B., Bilir, L., İlken, Z., Effect of geometrical parameters on heat transfer and pressure drop characteristics of plate fin and tube heat exchangers. Appl. Therm. Eng., 25, 24212431 (2005).

F. Incorporated, FLUENT 6.2 User's Guide: Fluent Incorporated Lebanon, NH, USA, (2004).

Huzayyin, A. S., Nada, S. A., Elattar, H. F., Air-side performance of a wavy-finned-tube direct expansion cooling and dehumidifying air coil. Int. J. Refrig., 30, 230-244 (2007).

Kays, W. M., London, A. L., Compact Heat Exchangers. Third ed., McGraw-Hill, New York (1984).

Krose, B., van der Smagt, P., An introduction to neural networks, Faculty of Mathematics \& Computer Science Institute of Robotics and System Dynamics University of Amsterdam. Eighth edition (1996).

Leu, J. S., Wu, Y. H., Jang, J. Y., Heat transfer and fluid flow analysis in plate-fin and tube heat exchangers with a pair of block shape vortex generators. Int. J. Heat Mass Tran., 47, 43274338 (2004).

Manglik, R. M., Zhang, J., Muley, A., Low Reynolds number forced convection in three-dimensional wavy-plate-fin compact channels: fin density effects. Int. J. Heat Mass Tran., 48, 1439-1449 (2005).

Metwally, H. M., Manglik, R. M., Enhanced heat transfer due to curvature-induced lateral vortices in laminar flows in sinusoidal corrugated-plate channels. Int. J. Heat Mass Tran., 47, 2283-2292 (2004).

Pirompugd, W., Wongwises, S., Wang, C. C., Simultaneous heat and mass transfer characteristics for wavy fin-and-tube heat exchangers under dehumidifying conditions. Int. J. Heat Mass Tran., 49, 132-143 (2006).

Şahin, H. M., Dal, A. R., and Baysal, E., 3-D Numerical study on the correlation between variable inclined fin angles and thermal behavior in plate fin-tube heat exchanger. Appl. Therm. Eng., 27, 1806-1816 (2007).

Tao, Y. B., He, Y. L., Huang, J., Wu, Z. G., and Tao, W. Q., Three-dimensional numerical study of wavy fin-and-tube heat exchangers and field synergy principle analysis. Int. J. Heat Mass Tran., 59, 1163-1175 (2007).

Tian, L., He, Y., Tao, Y., Tao, W., A comparative study on the air-side performance of wavy finand-tube heat exchanger with punched delta winglets in staggered and in-line arrangements. Int. J. Therm. Sci., 48, 1765-1776 (2009).

Wang, C. C., Hwang, Y. M., Linb, Y. T., Empirical correlations for heat transfer and flow friction characteristics of herringbone wavy fin-and-tube heat exchangers. Int. J. Refrig., 25, 673-680 (2002).

Wena, M. Y., Ho, C. Y., Heat-transfer enhancement in fin-and-tube heat exchanger with improved fin design. Appl. Therm. Eng., 29, 1050-1057 (2009).

Wongwises, S., Chokeman, Y., Effect of fin pitch and number of tube rows on the air side performance of herringbone wavy fin and tube heat exchangers. Energ. Convers. Manage., 46, 2216-2231 (2005).

Xie, G., Wang, Q., Sunden, B., Parametric study and multiple correlations on air-side heat transfer and friction characteristics of fin-and-tube heat exchangers with large number of large-diameter tube rows. Appl. Therm. Eng., 29, 1-16 (2009).

Yan, W. M., Sheen, P. J., Heat transfer and friction characteristics of fin-and-tube heat exchangers. Int. J. Heat Mass Tran., 43, 1651-1659 (2000).

Yang, S. M., Tao, W. Q., Heat Transfer. Third ed., China, Beijing (1998).

Zhang, J., Kundu, J., Manglik, R. M., Effect of fin waviness and spacing on the lateral vortex structure and laminar heat transfer in wavy-platefin cores. Int. J. Heat Mass Tran., 47, 1719-1730 (2004).

Zhu, Y., Li, Y., Three-Dimensional Numerical Simulation on the Laminar Flow and Heat Transfer in Four Basic Fins of Plate-Fin Heat Exchangers, J. Heat. Tran., 130, 111801-111808 (2008). 